\title{
Privatização em educação E formas de mercadoria ${ }^{1}$
}

GLEnN Rikowski*

RESUMO: Os trabalhos e pesquisas sobre a privatização da educação têm passado ao largo de seu significado mais importante: o desenvolvimento do capital através da profunda capitalização da educação. A discussão sobre a privatização educacional geralmente ignora sua implicação na produção social da força de trabalho. Com base em Karl Marx, esta contribuição leva mais além a crítica à privatização na educação, ao focar nas formas da educação como mercadoria e suas relações com a capitalização dos serviços educacionais. Consequentemente, os pontos de resistência à privatização na educação são aguçados para servirem como armas anticapitalistas.

Palavras-chave: Privatização da educação. Educação e formas da mercadoria. Capitalização dos serviços educacionais.

\section{Privatisation in Education}

And commodity forms

\begin{abstract}
Works and scholarship on privatisation in education have ignored one of its most important aspects: the development of capital through deep capitalization of education Furthermore, discussion on educational privatization typically ignores its implication in the social production of labor-power. Therefore, with reference to Karl Marx, this contribution drives the critique of privatization in education forward by focusing on commodity form (s) in education and their relations to the capitalization of educational services. Consequently, the points of resistance to privatization in education are sharpened the anti-capitalist weapons.
\end{abstract}

* É pesquisador independente da área de educação, estabelecido em Londres. Foi professor titular da University of Northampton. Atualmente é professor visitante da Faculdade de Ciências Sociais da University of Lincoln. É membro da Sociedade de Filosofia da Educação da Grã-Bretanha (PESGB, London Branch). Lincoln, Rein Unido. E-mail: <rikowskigr@aol.com>. 
Keywords: Privatisation in education. Education and commodity forms. Capitalisation of educational services.

\section{Privatización en educación \\ Y formas de mercancía}

RESUMEN: Los trabajos e investigaciones sobre la privatización de la educación han pasado más allá de su significado más importante: el desarrollo del capital a través de la profunda capitalización de la educación. La discusión sobre la privatización educativa generalmente ignora su implicación en la producción social de la fuerza de trabajo. Con base en Karl Marx, esta contribución lleva más allá la crítica a la privatización en la educación, al enfocarse en las formas de la educación como mercancía y sus relaciones con la capitalización de los servicios educativos. En consecuencia, los puntos de resistencia a la privatización en la educación se ven a servir como armas anticapitalistas.

Palabras clave: Privatización de la educación. Educación y formas de mercancía. Capitalización de los servicios educativos.

\section{La Privatisation dans l'éducation}

\section{Et les formes de marchandise}

RÉSUMÉ: Les travaux et les recherches sur la privatisation de l'éducation ont ignoré sa signification la plus importante: le développement du capital à travers la profonde capitalisation de l'éducation. La discussion sur la privatisation éducationnelle ne tient pas compte de son implication dans la production sociale de la force de travail. Fondée sur Karl Marx, cete contribution radicalise la critique de la privatisation de l'éducation, en se concentrant sur les formes d'éducation comme marchandise et leurs relations avec la capitalisation des services éducatifs. Par conséquent, les points de résistance à la privatisation de l'éducation sont aiguisés pour servir d'armes anti-capitalistes.

Mots-clés: Privatisation de l'éducation. Éducation et formes de marchandise. Capitalisation des services éducatifs. 


\section{Introdução}

A privatização na educação não é essencialmente sobre educação. Trata-se do desenvolvimento do capitalismo e do aprofundamento do domínio do capital em instituições específicas (escolas, faculdades, universidades etc.) na sociedade contemporânea. É claro que não é assim que a situação aparece na literatura acadêmica relevante. A privatização na e da educação é tipicamente enquadrada dentro de um discurso sobre se "funciona" ou não; ou se os aspectos da educação - padrões, equidade e eficiência em particular são reforçados ou ameaçados pela privatização em instituições educacionais. O foco na "mercadificação"2 da educação está particularmente em primeiro plano nos artigos e pesquisas sobre privatização educacional. O que permanece amplamente ignorado nessas abordagens acadêmicas padrão é a natureza das formas de mercadoria que são trabalhadas, desenvolvidas e expandidas nos processos de privatização educacional. Este artigo parte dessas formas de mercadoria, a fim de estabelecer um caminho para a crítica da privatização à educação que vai mais a fundo do que os relatos acadêmicos convencionais.

O trabalho teórico atual sobre a privatização da educação é inadequado como ponto de partida para entender o que está em jogo na crítica da privatização educacional enquanto desenvolvimento capitalista. Conforme Francine Menashy (2013) salienta, três das "abordagens mais comumente adotadas" para analisar a privatização educacional são os neoclássicos neoliberais, os bens básicos sociais e as abordagens baseadas em direitos (p.13). Ela considera todos os três fracos em seu poder explicativo em relação à privatização na educação, em comparação com sua própria escolha teórica: a abordagem da capacidade. Enquanto isso, Verger, Fontdevila e Zancajo (2016) defendem a "perspectiva da economia política" (p.6) para analisar a privatização educacional, em oposição à crítica da economia política.

Não há espaço aqui para elaborar uma crítica dessas cinco bases teóricas para analisar detalhadamente a privatização educacional. No entanto, faz sentido evitar todas essas abordagens, uma vez que elas não conseguem abordar a desconexão teórica entre a privatização na educação, a mercantilização e as formas de mercado. Em vez disso, este artigo baseia-se nas ideias do autor que mais aguçadamente escreveu sobre as mercadorias e suas formas na sociedade contemporânea: Karl Marx.

\section{Formas de mercadoria}

Sem nos estender muito a respeito da natureza da mercadoria na sociedade capitalista ou as noções de forma e forma social, o que se pode afirmar é que, para Marx, existem duas formas de mercadorias distintas. Isto é mais aparente em Teorias sobre a Mais-Valia: Parte 1 (Marx, 1863), quando Marx observa que: 


\begin{abstract}
O trabalho em si, em sua essência, na sua existência viva, não pode ser percebido diretamente como uma mercadoria, mas somente a força de trabalho, do qual o trabalho em si é a manifestação temporária.... [...]... Uma mercadoria deve, portanto, ser concebida como algo diferente do próprio trabalho. Portanto, o mundo das mercadorias é dividido em duas grandes categorias: de um lado, a força de trabalho. Do outro lado, as mercadorias em si (p. 171 - grifos do autor).
\end{abstract}

Portanto, existe a força de trabalho, que é a única "classe em si", a única mercadoria na sociedade capitalista que pode criar novo valor, mais-valia, à medida que se transforma em trabalho no processo de trabalho capitalista; e, por outro lado, existe a classe geral das mercadorias, que são todas as outras mercadorias, exceto a força de trabalho.

De acordo com Marx, a força de trabalho é uma mercadoria estranha, já que existe dentro do corpo do trabalhador, enquanto que todos os exemplos da classe geral de mercadorias estão situados fora do corpo do trabalhador. No entanto, esta fenda está desaparecendo na sociedade contemporânea; marca-passos cardíacos, articulações artificiais, aparelhos auditivos e outros produtos que melhoram a vida, estão atualmente alojados dentro dos corpos de alguns humanos. Eu deixo de lado os argumentos acadêmicos sobre se esses auxílios ao funcionamento humano são incorporados ontologicamente como elementos dos corpos dos seres humanos, ou se são ontologicamente distintas. Marx define a força de trabalho da seguinte maneira no primeiro volume do Capital:

Deve-se entender por força de trabalho ou capacidade de trabalho o agregado das capacidades intelectuais e físicas existentes em um ser humano, que ele exerce sempre que produz um valor de uso de qualquer ordem (Marx, 1867, p.164).

O que deve ser notado aqui é que esta descrição da força de trabalho é mais ampla e mais geral do que a matriz de atributos que tipicamente constitui "capital humano" na teoria do capital humano. Além disso, como já argumentei em textos anteriores (Rikowski, 2000, 2002) com relação às "capacidades intelectuais" dos trabalhadores, o trabalho e as atitudes sociais devem ser incorporados dentro de uma concepção de força de trabalho. Isso ocorre porque a força de trabalho está sob o controle da vontade do trabalhador; uma situação muito insatisfatória para os sujeitos porta-vozes do capital. O trabalhador deve ser encorajado, incentivado e forçado (dentro das leis do contrato, emprego e criminalidade) a despender trabalho efetivo e eficiente no processo de trabalho capitalista na busca de produção de mais-valia.

O importante a registrar aqui é que, na literatura acadêmica sobre privatização educacional, a privatização da produção da força de trabalho é invariavelmente ignorada. As instituições de educação e de formação de professores estão envolvidas na produção social da força de trabalho (Rikowski, 1990). Assim, quando são privatizadas, as atividades, processos e formas pedagógicas envolvidas na produção de força de trabalho também são necessariamente privatizadas. 
Passando agora para a classe geral de mercadorias. Embora no primeiro volume do Capital, Marx use as mercadorias físicas "duras" como exemplos em suas ilustrações sobre a natureza das mercadorias e a formação do valor de troca, a classe geral também pode incluir tanto bens imateriais como bens sólidos e materiais (graxa de botas, casacos, linho e trigo etc.). As mercadorias de classe geral podem ser imateriais, fragmentárias ou ter uma existência estritamente limitada no tempo, tais como performances dramáticas ou serviços de transporte. Marx examina esses casos em profundidade na primeira parte de Teorias sobre a Mais-Valia (Marx, 1863) e Fiona Tregenna (2009) argumenta de forma convincente aquilo que pode ser chamado de "serviços" (por exemplo, de cabeleireiro, de garagem, bem como educação e serviços de saúde) e que também podem ser mercadorias para Marx (pp. 7-9). Conforme Ryder (2017) indica:

Os exemplos de Marx [no Capital, volume I] geralmente se referem a produtos físicos, como casacos ou mesas, mas... a mesma dinâmica se aplica a códigos de escrita da era digital ou a ensino ou apresentações musicais ou o que quer que seja (p.4).

De fato, no Capital, Marx cita o exemplo das escolas particulares como sendo meios de produção para a criação de valor. Eles podem ser como "fábricas de salsicha" (Marx, 1867, p.477).

O ponto essencial é que as mercadorias incorporam valor (que aparece como valor de troca quando são comparadas através da forma monetária como preço) e, a partir da perspectiva do funcionamento e expansão do sistema de capital, a mais-valia. A natureza da mercadoria neste processo é irrelevante para Marx. Assim: "as mercadorias não se limitam à bens físicos e, de modo semelhante, a 'produção' não se limita à produção física de um objeto tangível" (Tregenna, 2009, p.8).

\section{Privatização na educação}

Essa seção trata das noções de privatização em geral e privatização na educação em particular e é precedida de uma breve discussão que situa a privatização em seus antecedentes históricos e contextuais.

As fortunas da sociedade capitalista mudaram radicalmente no final do boom pós-guerra no início da metade dos anos 70. Conforme observou Andrew Kliman (2012), desde a década de 1970, a sociedade capitalista enfrenta uma queda na taxa de lucro no setor manufatureiro. Quando o Muro de Berlim caiu e a Rússia e o Bloco Oriental foram incorporados ao sistema capitalista mundial, juntamente com o desenvolvimento capitalista da China, houve uma resposta triunfalista das forças pró-capitalista. Isto foi rapidamente atenuado pela recessão do início da década de 1990 e pela crise econômica no Extremo Oriente (por exemplo, Coréia do Sul). O fanatismo milenar em relação às 
tecnologias computadorizadas e o boom associado às empresas ponto-com, de 1997 a 2001, também se evaporaram com uma grande reestruturação das empresas online em 2000-2002. Um golpe mais duro para o desenvolvimento capitalista veio com a Grande Recessão de 2007-09 e a Grande Depressão, que veio em seguida (Roberts, 2016). O reticente socorro aos bancos, a flexibilização quantitativa ${ }^{3}$, a queda no padrão de vida dos trabalhadores e as crises da dívida pública tiveram consequências negativas para o investimento em manufatura, embora a flexibilização quantitativa (QE) tenha ajudado os bancos e financiado o capital nos investimentos em imóveis e títulos (com altas recordes em muitos mercados financeiros mundiais no ano passado).

De acordo com Kliman (2012), a única maneira de aumentar as taxas de lucro no capital industrial contemporâneo é por meio de um conflito bélico de grandes proporções e a destruição de quantidades significativas de capital em todo o mundo, ou uma decisão por parte da comunidade capitalista internacional e Estados nacionais associados, de modo a produzir um colapso econômico, que eliminaria vastas porções do capital, desvalorizando o capital sobrevivente e prejudicando o valor da força de trabalho através de grandes cortes nos salários em uma escala nunca antes vista na história capitalista. Conforme Kliman argumenta, nenhuma destas opções atrai os sujeitos, porta-vozes do capital; os riscos políticos são grandes demais. Assim, o sistema capitalista continua a cambalear adiante.

A situação atual é agravada por dois fatores relacionados. Em primeiro lugar, o estudo recente a respeito dos efeitos da marcha da tecnologia informática (por exemplo, Srnicek e Williams, 2015 e Mason, 2016), indica que a força de trabalho será deslocada para fora do setor manufatureiro, mas também para fora do setor de serviços, nos próximos anos, em uma escala cada vez maior. Isto terá um impacto negativo adicional sobre as taxas de lucro, uma vez que o trabalho, fonte de um novo valor, é deslocado dos processos de trabalho capitalistas. Em segundo lugar, o deslocamento do trabalho significa que não está sendo criado um valor suficiente para sustentar o desenvolvimento capitalista e a civilização (Kurz, 2016).

Nessas circunstâncias desesperadas para o capital global, o financiamento estatal da educação aparece como uma fonte tentadora para sugar dinheiro público. $\mathrm{O}$ valor do mercado educacional mundial foi de \$ 4,9 trilhões (USD) em 2015 (Verger et al, 2017, p.325). O investimento em capital de risco em educação foi de quase US $\$ 2$ bilhões (USD) em 2014, mostrando um aumento de 45\% em 2009-2014 durante os anos da Grande Depressão (Ibid.). Nessas circunstâncias, a tomada de controle sobre a educação por parte das empresas não parece surpreendente, o que estimula a sua privatização.

Então, o que é a privatização na educação? Esta não é uma pergunta tão simples quanto parece. Um foco central na literatura acadêmica tem sido a respeito de certas questões recorrentes ou as consequências negativas de privatizações reais ou potenciais na educação, que são usadas para definir implicitamente sua natureza. Destas questões 
recorrentes que colocam a privatização sob uma luz negativa estão, por exemplo, a de que a privatização educacional: prejudicará os padrões de ensino, aprendizagem e resultados educacionais (CASE, 2011; Klees, 2006; Muir, 2012; TUC, 2014); contribuirá para a redução do salário dos professores (Muir, 2012 e Klees, 2006) piorando as condições de trabalho (TUC, 2014); permitirá que assistentes de sala de aula e pessoal de apoio fiquem mais suscetíveis de ser demitidos (TUC, 2014); dificultará o planejamento (local, regional e nacional) (CASE, 2011, Heartfield, 2009); colocará a representação sindical em risco (Verger et al, 2017 e Klees, 2006); tornará o currículo e a pedagogia mais padronizados (para economizar custos) tornando-os menos estimulante para estudantes (McMurtry, 1991; e Verger et al, 2017); irá corroer os valores do serviço público (Muir, 2012); facilitará a corrupção (McMurtry, 1991; Saltman, 2006; Spreen et al, 2006; e TUC, 2014); irá comprometer a equidade e a igualdade e fará com que a discriminação seja mais comum (Spreen et al., 2006; TUC, 2014); e aumentará a segregação (por raça e etnia em particular) (CASE, 2011; TUC, 2014).

Listar as consequências e características negativas da privatização na educação diz algo de suas características, e adicionar a este cálculo os seus supostos aspectos positivos poderia resultar em uma conta mais arredondada, mas este procedimento evita lidar com a natureza, com seu modo de existência, seja com a privatização ou com suas formas fenomenais. Poucos teóricos educacionais tentam definições ou caracterizações de privatização e privatização educacional. Quando o fazem, são principalmente em relação às suas várias dimensões, formas ou tipos. O nó da questão, a natureza da privatização educacional, geralmente é evitado. Assim, as lacunas são preenchidas, ao mesmo tempo em que indicam as limitações das concepções existentes.

Como ponto de partida, percebe-se que existem duas formas básicas de privatização. Primeiro, há o que poderia ser chamado de Privatização Clássica, como exemplificado na privatização do regime Thatcher de serviços públicos (por exemplo, gás, eletricidade e água) no Reino Unido, na década de 1980. Isso também pode ser visto como privatização "direta". Envolve a venda de ativos públicos diretamente para alguma combinação de empresas, grupos de investidores e investidores individuais. Portanto, Saltman (2007) está incorreto ao anunciar, em uma declaração que ele fizera no ano anterior (Saltman, 2006, p.341), que "as iniciativas de privatização mais diretas incluem as empresas que administram escolas públicas com fins lucrativos", que ele chama de "contratação por desempenho" (p.269). A abordagem de Saltman confunde a questão da propriedade/ controle de instituições ou processos educacionais no advento da privatização. Mas, mesmo com a Privatização Clássica, os órgãos reguladores governamentais (com poderes variados em relação ao preço, qualidade de entrega e propriedade, com concursos para prestadores de serviços como objetivos declarados bem como com suas medidas para evitar o monopólio) podem ser instituídos pelos Estados. No entanto, esta rota não é tipicamente seguida para a privatização na educação em países capitalistas avançados. 
Na segunda forma de privatização, a transferência da propriedade dos ativos do setor público para o privado não ocorre. Em vez disso, a propriedade absoluta das instituições educacionais é evitada e o controle sobre elas vem à tona. Isto é o que eu chamei em outro momento (Rikowski, 2003) de, "a tomada de controle sobre a educação por parte das empresas", em oposição à sua privatização direta. Quando autores e pesquisadores em educação apontam para "privatização" na educação é a isto que eles tipicamente aludem; a tomada de controle sobre a educação por parte das empresas que não envolvem propriedade. É claro que isso pode ser um estágio no caminho da privatização completa ou clássica e direta. A tomada de controle sobre a educação por parte das empresas está baseada no contrato. Isso pode ser entre governos locais, regionais ou nacionais e suas agências e prestadores privados de educação. Tais contratos estipularão diversos objetivos a serem cumpridos (com sanções em caso de não cumprimento), os lucros podem ser limitados (ou ilimitados), e estes contratos podem estar vinculados a várias iniciativas ou prioridades de políticas governamentais e podem sancionar várias formas de desregulamentação (por exemplo, salário dos professores, procedimentos de recrutamento, contra o reconhecimento de sindicatos, patrimônio e imóveis e assim por diante). Tais contratos geralmente são muito sigilosos, portanto, os detalhes precisos são geralmente desconhecidos. O ponto essencial é que o prestador privado aproveita a diferença entre os pagamentos feitos por governos locais, regionais ou nacionais para gerir instituições ou serviços educacionais e o que custa para administrá-los. Há uma força motriz para gerir esses serviços educacionais e instituições abaixo do preço do contrato, a fim de obter lucros - com correspondentes apertos no salário dos professores, condições, auxílios educacionais etc. - e tentativas relacionadas a obter maiores lucros através da venda de terra (por exemplo, campos de esporte) ou alugando espaços institucionais (por exemplo, salas para reuniões e eventos). Assim, a noção de que a privatização da educação é mais eficiente do que o prestador estatal, como defendido por muitos de seus apoiadores, é contraintuitiva. O lucro é um custo extra que os prestadores públicos não possuem (embora obviamente eles tenham que trabalhar dentro dos orçamentos). Portanto, a necessidade de apertar orçamentos e aumentar a carga horária dos professores torna-se uma necessidade pós-privatização, e a busca de outras medidas de redução de custos torna-se uma prioridade.

Esta segunda forma de privatização, a tomada de controle sobre a educação por parte das empresas, poderia ser dividida em várias formas, talvez começando com a privatização dos serviços educacionais como o encontro educacional entre professores e alunos - onde os professores poderiam ser trabalhadores de agências ou empregados de uma corporação - e depois explorando os meios de produção educacional (imóveis, livros, salas de aula, equipamentos de ginástica). Isso torna a análise mais complexa, mas salta à frente de várias ideias-chave que precisam ser articuladas em primeiro lugar. 
O ponto principal nesta fase da análise é que ao enfocar na distinção de aquisição Clássica (direta) / a tomada de controle sobre a educação por parte das empresas não se chega ao cerne da questão da privatização em geral e nem a privatização educacional em particular. Isto é porque ambas as formas dependem da conversão da receita do Estado em lucro privado através da "magia do dinheiro". O dinheiro muda sua forma, seu modo de existência na privatização da educação (ou qualquer outro serviço público ou de utilidade pública). É transformado em lucro. Os interesses corporativos, vários fundos de investimento e de pessoas físicas procuram abocanhar alguns dos $\$ 4,9$ trilhões (USD) de financiamento público para educação e transformá-lo em lucro através da administração ou compra de instituições e serviços educacionais. Saltman (2014, pp.249-250) compreende esse aspecto ao mesmo tempo em que confunde a questão ao afirmar que é a redefinição de “bens e serviços públicos como bens privados" o ponto-chave (p.252), em vez de uma transformação da forma social do dinheiro. Fitz e Beers (2002) conseguem abordar melhor a questão quando argumentam que a privatização envolve a "transferência de dinheiro ou ativos privados do domínio público para o setor privado" (p.139 - grifos meus, em Verger et al, 2016, p. 7), embora a transformação da receita do Estado em lucro privado seja obscurecida nesta formulação. O dinheiro não é privado até que tenha sido transformado de receita do Estado em lucro privado.

É esse desenvolvimento que destaca o fato de que a privatização da educação não é realmente sobre educação: trata-se de se beneficiar da receita do Estado e transformá-la em lucro. A menos que este ponto seja o foco, a política de privatização em instituições e serviços educacionais torna-se opaca. Assim, a grande quantidade de artigos que passaram a debater se a privatização da educação aumenta os padrões educacionais (ou não), ou ajuda vários grupos de estudantes a competir nos mercados de trabalho (ou não), falham em um ponto essencial e esses argumentos acabam saindo pela tangente. A política de privatização educacional (ou de qualquer outra forma) é a obtenção de lucros, que por sua vez se baseia na capitalização de instituições e serviços educacionais; educação tornando-se capital. Trata-se do desenvolvimento capitalista na educação. Assim, iniciar discussões de privatização educacional a partir de suas principais formas (conforme descrito acima) também é inadequado para compreender a essência da privatização: a conversão da receita do Estado em lucro privado.

\section{A Fragilidade da privatização na educação}

Lucrar com instituições educacionais, encontros de ensino e aprendizagem, produção de força de trabalho e políticas educacionais é um processo frágil. Esta fragilidade se baseia em, pelo menos, três considerações. 
Primeiro, há o problema da regulamentação estatal - seja o excesso de regulamentação, pela perspectiva do capital, ou seja, "burocracia” demais que atrapalha a lucratividade na privatização na educação; ou os modelos para sugar receitas do estado e transformá-los em lucro privado não foram suficientemente desenvolvidos (o que talvez repouse substancialmente no primeiro exemplo, já que o estado "fica no caminho atravancando" os modelos com fins lucrativos). Assim, para os EUA, as observações de Saltman (2010) estão atreladas a ambos os fatores:

Até o momento, as evidências mostram que não é possível gerir lucros para as escolas, e fornecer, ao mesmo tempo, recursos adequados para a educação pública (p.19).

Saltman observa que este é o caso, seja lá qual for a forma de privatização educacional. Ele também indicou que é contraintuitivo pensar que os operadores do setor privado poderiam lucrar sem baixar os salários dos professores, piorar as condições e os benefícios e perseguir os sindicatos - e conciliar isto com o aumento dos padrões educacionais. Saltman (2007) apontou, ainda em 2002, que a imprensa empresarial havia percebido que lucros significativos não seriam alcançados através da administração de instituições educacionais. Em 2009, Stephen Ball observou que o "mercado de terceirização institucional na educação no Reino Unido está virtualmente moribundo no momento" e "os empreendedores educacionais estão pessimistas quanto à vontade política para o crescimento futuro" da tomada de controle sobre a educação por parte das empresas (p.84). O governo do Reino Unido, aparentemente, não estava desregulamentando as instituições educacionais o suficiente para que os investidores privados ganhassem uma posição significativa. Conforme Ball afirmou: "A privatização e o Estado precisam ser pensados juntos" (2009, p.97). No entanto, esses estudos dos EUA e do Reino Unido contam apenas uma parte da história. Em outras partes do mundo, o governo local, regional e central, sindicatos de professores, a mídia, os críticos acadêmicos e outros grupos de resistentes à privatização não apresentaram um bloqueio à lucratividade na educação. Assim, Verger et al (2016) apontam para uma "indústria de educação global" (Global Education Industry, GEI na sigla em inglês) em seu monumental estudo de privatização educacional. Verger et al (2017) indicam o "crescimento aparentemente inexorável" na GEI. No entanto, os casos dos EUA e do Reino Unido mostram que o desenvolvimento da GEI é frágil em alguns países capitalistas avançados.

Um segundo problema é que nem todas as experiências em privatização educacional são bem-sucedidas ou sustentadas (Ball, 2009). O estudo clássico de Saltman (2005) sobre a ascensão e queda das escolas Edison nos EUA é um exemplo. Instâncias de corrupção, nepotismo e favoritismo (TUC, 2014, p.4), quando as empresas foram liberadas para entrar nas escolas na Inglaterra, contribuem para a licenciosidade, a torpeza moral e o oportunismo político subjacente à fragilidade da privatização educacional. 
Em terceiro lugar, as críticas de sindicatos, de jornalistas céticos (muitas vezes recrutando professores em seus relatórios) e, especialmente, de pesquisadores acadêmicos, teóricos e comentaristas infestaram o "movimento de privatização" educacional (Rizvi, 2016, p.3). Isto aumenta sua fragilidade. É claro que, nos círculos acadêmicos em particular, houve debates ferozes sobre a conveniência e a eficácia da privatização educacional. Os a favor da privatização reagiram, pressionando os governos, com relatórios de grupos de opinião radical de direita (os chamados think-tanks), com acadêmicos pró-capitalistas e de direita e, em alguns casos, com ministros da educação (por exemplo, Michael Gove, Ministro da Educação do Reino Unido, 2010-2014), defendendo a privatização educacional.

O problema para os protagonistas da privatização educacional é que "eles precisam se comunicar e convencer as outras partes interessadas na educação, usando a linguagem da educação", de que a privatização é uma coisa boa (Verger et al, 2017, p.331 - grifos meus). Mesmo que eles possam convencer os legisladores, esses mesmos legisladores precisam convencer as outras partes interessadas em educação de que uma reforma da privatização é "boa para o aluno, ou melhor ainda, melhora os resultados de aprendizagem" (Ibid.). A evidência não é favorável aos que pregam a privatização. Verger et al apontam para "batalhas ferozes de ideias e evidências", onde aqueles a favor da privatização na educação, especialmente os partidários do governo, têm que convencer de que suas ideias sobre privatização educacional “funcionarão" (2017, p.336). Menashy (2013) argumenta que o aumento da presença de prestadores privados de educação na educação através de parcerias público-privadas e escolas privadas com mensalidades acessíveis "gerou um consequente aumento de críticas" (p.21).

Apesar da condição frágil de projetos de privatização educacional, especialmente em muitos dos países capitalistas avançados, é de se esperar que a atração exercida pelos orçamentos mundiais destinados à educação estatal alimentará o interesse dos investidores e corporações para continuar a bater nas portas dos governos para ter acesso ao mercado da educação. À medida que o capitalismo se decompõe (Jappe, 2017), pesquisas desesperadas por novas fontes de valor direcionarão as corporações para áreas inóspitas na busca de lucros. Isso está de acordo com o Devir do capital e ao seu expansivo e intensivo desenvolvimento.

\section{Devir do capital e capitalização da educação}

Em Grundrisse, Marx indica que o desenvolvimento do capitalismo pode ser visto como um processo, "o Devir do capital” (1858, p. 310). Em relação à educação, o Devir do capital refere-se, portanto, aos processos envolvidos em sua capitalização: a educação tornando-se capital. Para entender o desenvolvimento do capital, como ele emerge, 
muda, se espalha e se intensifica, argumenta Marx, precisamos entender o "processo dialético de seu Devir... [que]... é apenas a expressão ideal do movimento real através do qual o capital se desenvolve" (1858, p.310). Para Marx, o capital está sempre em processo de tornar-se à medida que se desenvolve e muda continuamente. No entanto, quando se expande para campos relativamente novos, como educação estatal (ou pública), o movimento real do capital pode ser observado. Parar, acabar com ou, pelo menos, resistir a este "movimento real" é uma possibilidade. Como Marx observa:

As condições e os pressupostos do devir, da gênese do capital, supõem precisamente que ele ainda não é, mas só devém; (1858, pág. 459 - grifos do autor).

Assim, a privatização na educação, nesse sentido, está em um estado de devir: os produtos das instituições educacionais estão em processo de capitalização, tornando-se capital.

A privatização (tantos nas formas clássicas quanto na tomada de controle sobre a educação por parte das empresas) é apenas uma dimensão da educação, tornando-se capitalizada. A capitalização da educação inclui pelo menos os seguintes desenvolvimentos futuros (mercantilização também essencial): geração e formação das duas formas de mercadorias (força de trabalho e classe geral), como observado anteriormente e a mercantilização (marketization) onde os mercados educacionais devem ser estabelecidos. Enquanto na literatura acadêmica há um amplo foco nos processos de comercialização na educação, normalmente não há uma relação com a mercantilização e, ainda mais, com o Devir do capital, com a capitalização da educação. Na literatura anglófona dos anos 80 e 90, a obsessão com a "mercadificação" educacional ignorou quase totalmente o que eram as mercadorias reais trocadas nos mercados educacionais! Assim, escrevi um artigo chamado Education Markets and Missing Products (Mercados educacionais e perdas produtivas), que assinala esta situação bizarra (Rikowski, 1996). Além disso, há uma tendência a atribuir demais aos mercados educacionais; para dar-lhes excesso de importância em relação às outras dimensões da capitalização. Por exemplo, Saltman começa um de seus artigos com a seguinte declaração:

A privatização da educação envolve a transformação da escolaridade pública no modelo do mercado (2007, p. 269).

A capitalização continua pouco conhecida. É lógico que o estabelecimento de mercados educacionais é crucial para a capitalização da educação, mas é insuficiente para sua realização. A mercantilização deve ir de mãos dadas com a "mercadificação", e outras dimensões devem ser desenvolvidas se o capital for efetivamente subsumir a educação dentro de sua órbita.

A commercialisation ${ }^{5}$ é outro aspecto. Há uma série de elementos. A commercialisation na educação está essencialmente relacionada com publicidade e a arte da persuasão. 
Assim, abrange as tentativas de redes de representantes do capital favoráveis à privatização, máquinas de relações-públicas, organizações de lobby, meios de comunicação simpáticos à privatização, declarações públicas de gerentes do alto escalão e executivos de corporações, grupos de opinião radical de direita (os chamados think-tanks) e as conclamações dos partidários da privatização em educação para convencer em relação a uma necessidade percebida das políticas que a promovam. A superioridade da privatização para a prestação pública também é defendida, e "evidências" são reunidas. Declarações tais como as de Fazal Rizvi, quando ele diz que "a educação não pode mais ser totalmente financiada e fornecida pelo Estado" (2016, p.1) abrem a porta para essas ideias. A privatização da própria política educacional é relevante aqui. Como Ball (2009) mostrou, corporações como a Price Waterhouse Coopers estão envolvidas em um volume considerável de pesquisa, avaliação, assessoria, auditoria e trabalho de consulta com o Departamento de Educação da Inglaterra. Seria ingênuo presumir que suas recomendações ao Departamento seriam inteiramente imparciais em relação à capitalização da educação. Em segundo lugar, há uma comercialização na educação. Isso inclui propaganda em livros didáticos e produtos de TI, nos corredores escolares, em programas de TV assistidos nas escolas e em várias formas de patrocínio e filantropia que anunciam produtos ou o suposto mérito de filantropos que contribuem para a educação distribuindo alguns de seus milhões (por exemplo, Bill Gates).

Em terceiro lugar, quando as escolas, colégios e universidades desenvolvem suas próprias mercadorias educacionais ou corporações desenvolvem-nas em parceria com instituições educacionais (por exemplo, examination aids ${ }^{6}$, vídeos educacionais, vídeo-aulas, software), estes devem ser anunciados para promoverem vendas.

Em quarto lugar, as empresas que vendem produtos educacionais se envolvem em campanhas publicitárias dirigidas a profissionais e gerentes do alto escalão.

Em quinto lugar, há o crescente mercado de tecnologia da informação para coisas como marking ${ }^{7}$, avaliação, monitoramento (por exemplo, a realização, atendimento e apresentação de cursos) e vigilância (por exemplo, circuito fechado de televisão) que requerem publicidade. Não há dúvida de que existem outras formas de comercialização além destas, mas este enorme esforço faz duas coisas: em primeiro lugar, apoia a capitalização da educação em geral; em segundo lugar, a capitalização da educação é aumentada por toda uma gama de mercadorias consideradas essenciais (em termos de controle gerencial, vigilância, custo e o status que os programas dão a determinada instituição de ensino) para o desempenho em contextos educacionais contemporâneos.

A monetização é outro aspecto da capitalização da educação. Atividades, produtos, processos e procedimentos recebem preço, é aferido a eles um valor monetário. É lógico que a monetização é um processo que pode ser feito independentemente da capitalização, mas também é uma característica essencial dela. Além disso, ela pode estar ligada (mas não reduzida) ao que foi chamado de financeirização na educação. A monetização na 
educação também está ligada à medição de serviços educacionais, que por sua vez podem ser divididos em padronização, garantia e controle de qualidade, relação custo-benefício e muitos outros conceitos subsidiários.

Finalmente, a capitalização pode ser diversificada com base na distinção entre os meios de produção educacional e suas mercadorias. Assim, os meios de produção de mercadorias educacionais podem eles mesmos ser mercadorias (por exemplo, campos de jogo das escolas, que podem ser vendidos).

Compreender a capitalização da educação envolve a compreensão das conexões entre todas essas dimensões. No discurso acadêmico, em geral, elas são tipicamente separadas. Por conseguinte, haverá um foco na privatização com pouca referência à mercantilização ou à "mercadificação", sem investigar as mercadorias educacionais trocadas e distribuídas nos mercados educacionais - tudo em detrimento do reconhecimento da capitalização. Essa fragmentação teórica e empírica na literatura acadêmica constitui uma fuga e evasão em relação à descoberta da força social da capitalização na educação. Embora as críticas da esquerda à privatização, por exemplo, pareçam radicais, são superficiais e evasivas se não conseguem relacioná-las às outras dimensões da capitalização, obscurecendo assim a capitalização da educação, o Devir do capital nas instituições educacionais. Isso é mais conveniente para os sujeitos representantes do capital. Mas, pior, situa a resistência à capitalização da educação numa base fraca e parcial; o significado real da privatização, da "mercadificação", etc., é perdido ao não reconhecer seu modo de existência como dimensões da capitalização.

Finalmente, as opiniões de Marx sobre a capitalização como um momento progressivo e "mais elevado" no desenvolvimento capitalista serão agora examinadas. Isso mostra que os opositores radicais à privatização tipicamente deixam de reconhecer as implicações totais que estão acontecendo. Em Grundrisse, Marx (1858) indica que a forma mais desenvolvida do capital e capitalismo não é quando as condições que compõem a reprodução social do capital são financiadas com a receita do Estado, mas quando o capital produz diretamente processos socialmente reprodutivos. Marx observa que:

\footnotetext{
O máximo desenvolvimento do capital se dá quando as condições gerais do processo de produção social não são criadas a partir da dedução da renda social, dos impostos do Estado - em que a renda, e não o capital, aparece como fundo de trabalho e o trabalhador, embora seja trabalhador assalariado livre como qualquer outro, economicamente se encontra em uma outra relação -, mas pelo capital como capital. Isso mostra, de um lado, o grau em que o capital já submeteu a si todas as condições da produção social e, por essa razão, de outro lado, a extensão com que a riqueza reprodutiva social está capitalizada e todas as necessidades são satisfeitas sob a forma da troca; bem como a extensão com que as necessidades do indivíduo, como necessidades socialmente postas, i.e., as que ele consome e precisa não como indivíduo singular na sociedade, mas coletivamente, com outros - cujo modo de consumo, pela natureza da coisa, é um modo social-, também estas são não só consumidas por meio da troca, da troca individual, mas também produzidas. ${ }^{8}$
} 
Tomando a Inglaterra como exemplo, o sistema escolar é uma forma socialmente reprodutiva no capitalismo contemporâneo. Isso ocorre porque está envolvido na produção da força de trabalho (a capacidade de trabalhar). Em um polo, o Estado financia (através da tributação) o funcionamento das escolas e também as dirige diretamente, tanto através do Estado central quanto através do Estado local ou regional, ou através de várias relações destes. Embora o valor e talvez até a mais-valia seja gerado nesse processo, não é qualquer parcela da mais-valia que é transformada em lucro. Por isso, nesta medida, o capital não foi totalmente subjugado na Inglaterra.

Por outro lado - durante o "maior desenvolvimento do capital" - o capital é dono e administra escolas a partir do próprio capital, sustentado por pagamentos (mensalidades) dos compradores (pais, empregadores ou estudantes) e gera valor e mais-valia. Alguns destes últimos são socialmente transformados em lucro - que chega as mãos de pessoas ou grupos de pessoas (sejam eles donos de escola, acionistas ou instituições). É quando o capital atua como capital no sistema escolar de forma mais desenvolvida. Como Marx observa no primeiro volume do Capital, quanto mais as escolas se aproximam dessas circunstâncias, mais se tornam "fábricas de ensino":

A produção capitalista não é meramente a produção de mercadorias, é essencialmente a produção de mais-valia. O trabalhador produz, não para si mesmo, mas para o capital. Já não basta, portanto, que ele simplesmente produza. Ele deve produzir mais-valia. Esse trabalhador sozinho é produtivo, ele produz mais-valia para o capitalista e, portanto, trabalha para a auto-expansão do capital. Se pudermos pegar um exemplo de fora da esfera da produção de objetos materiais, um professor é um trabalhador produtivo, quando, além de agredir verbalmente seus alunos, ele trabalha como um cavalo para enriquecer o proprietário da escola. Que o último estabeleceu seu capital em uma fábrica de ensino, em vez de em uma fábrica de salsicha, não altera a relação (Marx, 1867, p.477).

Mesmo algumas escolas privadas atualmente constituídas, que têm status de caridade na Inglaterra, não se aproximam do status de "fábricas de ensino" no sentido que Marx atribui, pois há um subdesenvolvimento da categoria do lucro. No entanto, operadores como GEMS e Cognita na Inglaterra, que operam redes de escolas privadas, se aproximam mais facilmente da forma de ensino que Marx descreve como a "fábrica de ensino". Nessas escolas, a mais-valia e especialmente o lucro adquirem uma definição social mais efetiva e clara.

Como se pode ver na citação sobre "o mais elevado desenvolvimento do capital" (Marx, 1867, p.477), Marx descreveu o processo de capitalização, onde aspectos e áreas da vida tornam-se subjugados pelo capital e funcionam como valor e mais-valia - gerando locais e práticas. Ele ressalta, em particular, que quanto maior o desenvolvimento do capital, mais "todas as condições de reprodução social" (que incluirão educação, saúde e outros serviços sociais) serão capitalizadas. Ele também enfatiza na mesma citação que o outro lado deste desenvolvimento é que as atividades comunitárias (como a educação) 
são simultaneamente transformadas em modos de consumo individualizados e produzidas "através do intercâmbio, da troca individual" (Marx, 1858, p.532). Assim, os mercados são desenvolvidos de forma correspondente como esses anteriormente comunais e as atividades são transformadas (ao longo do tempo) em mercadorias incorporando a mais-valia. Além disso, quanto maior o desenvolvimento do capital, quanto mais capitalização toma conta de uma atividade social e comunitária, tanto mais mercado é necessário para facilitar a realização de lucros nas trocas individuais. Conforme Marx observa:

O produto torna-se uma mercadoria, deixa a fase de produção, apenas quando está no mercado (Marx, 1858, p.672 - grifos do autor).

Além do mais:

Quanto mais desenvolvido o capital [...] quanto mais extenso o mercado em que circula, o qual forma a órbita espacial da sua circulação, tanto mais ele se esforça simultaneamente para uma extensão ainda maior do mercado e para uma maior aniquilação do espaço em relação ao tempo (Marx, 1858, p.539).

Por isso, torna-se clara a importância do setor de educação global. Além disso, ao afastar-se de um sistema estatal de escolas para uma tomada de controle sobre a educação por parte das empresas, o desenvolvimento de mercados no sistema escolar facilita o desenvolvimento do capital neste sistema. Os processos estão vinculados. Como observa Marx, existe uma tendência no capital para "criar o mercado mundial", que é "dado no próprio conceito de capital" (Marx, 1858, p. 408). De fato, uma "constante expansão do mercado torna-se uma necessidade para a produção capitalista" (Marx, 1866, pág. 967 - grifos do autor). Nesta base, a privatização da educação, como uma dimensão de sua capitalização, indica uma fase mais elevada do capitalismo em comparação às instituições e processos públicos de ensino. Portanto, bloquear a privatização é, ao mesmo tempo, prejudicar o desenvolvimento capitalista na educação, como restringir e destruir qualquer outro momento da capitalização da educação. A política anticapitalista na educação, portanto, deve se concentrar nessas considerações, que têm o efeito de atacar o desenvolvimento capitalista.

\section{Privatização na educação e as duas classes de mercadorias}

Antes de concluir, retomamos o ponto de partida: de volta às duas formas de mercadorias - e uma pequena expansão em relação ao seu significado.

Em primeiro lugar, a força de trabalho: a maravilhosa mercadoria que tem a capacidade, ao trabalhar no processo de trabalho capitalista, de criar valor para além do seu próprio valor, como representado no salário - a mais valia. A produção social da força 
de trabalho é institucionalmente fragmentada em vários tipos de instituições, de creches, escolas, faculdades e ensino superior, juntamente com a aprendizagem e formação profissional, organizações de treinamento e muitas outras instituições de aprendizagem e treinamento. Além disso, a força de trabalho é reforçada através do trabalho real no próprio processo de trabalho capitalista. Assim, algumas partes da produção social da força de trabalho podem estar nas mãos do Estado capitalista, enquanto outras são organizadas baseadas em instituições de caridade ou com fins lucrativos. No entanto, não se deve concluir que os casos de produção da força de trabalho pelo Estado não sejam problemáticos. Organizações estatais capitalistas moldam e formam forças de trabalho para exploração nos processos de trabalho capitalistas. Representantes do capital, a grande mídia, economistas (por exemplo, a teoria do capital humano) e pesquisadores acadêmicos fazem lobby e pressionam os Estados capitalistas a utilizar instituições de educação pública para várias formas de desenvolvimento da força de trabalho. Desde a Segunda Guerra Mundial, os sistemas e instituições de educação pública foram cada vez mais reduzidos a produtores de força de trabalho, muitas vezes a mando dos governos. Priorizar as Ciências Exatas sobre as Ciências Humanas e a ideologia da "empregabilidade" são alguns dos resultados. Com base neste cenário, dado o seu envolvimento na produção da força de trabalho, o Estado capitalista não é um refúgio anticapitalista. $\mathrm{Na}$ verdade, Marx argumentou na Crítica ao Programa de Gotha (1875) que "o governo e a igreja devem... ser igualmente excluídos de qualquer influência na escola" (p.31). É claro que a defesa dos empregos, do salário, da sindicalização e das condições dos trabalhadores nas instituições públicas de educação é essencial, mas isso não deve ser confundido com as lutas contra a redução da educação para a produção da força de trabalho.

Em segundo lugar, na classe geral de mercadorias, se um operador privado comprasse uma universidade ou a gerenciasse em um contrato com fins lucrativos, então eles teriam obtido um "pacote de mercadorias". Isso ocorre por dois motivos. Primeiro, não se pode dizer que a empresa "tenha comprado educação" ou ensino superior. Isso confundiria os processos educacionais (como processo de trabalho) com as mercadorias educacionais. Em segundo lugar, e mais importante, a universidade produz uma vasta gama de mercadorias ou incorpora mercadorias potenciais - desde o ensino, pesquisa e várias formas de comércio de mercadorias (por exemplo, patentes, informações, grande volume de dados, conferências etc.). Estes poderiam ser fatiados e picados em subpartes ou lançados como mercadorias singulares. No geral, a situação é mais parecida com os derivativos no setor financeiro onde hipotecas e empréstimos são "empacotados" em mercadorias e vendidos no mercado. Além disso, partes da operação de uma universidade poderiam ser comodificados (por exemplo, o auxílio aos estudantes estrangeiros aprendendo inglês, dos quais há vários exemplos em universidades do Reino Unido). Esta consideração aplica-se menos às faculdades, escolas e creches onde a gama de mercadorias potenciais é mais estreita, mas ainda assim é relevante: por exemplo, a aplicação 
de diferentes lições como matemática e biologia nas escolas poderia ser subcontratada a diferentes empresas.

\section{Conclusão: privatização na educação e desenvolvimento capitalista}

Este artigo argumentou que a privatização da educação é essencialmente sobre o desenvolvimento capitalista: a capitalização, o "Devir do capital” na educação. Transformar a receita do Estado em lucro privado é sua principal característica. Ao deter a privatização na educação, estamos bloqueando a expansão e a intensificação do capitalismo. A privatização da educação não é essencialmente a respeito da educação em si. A capitalização da educação prossegue através de suas formas de mercadoria, força de trabalho e a classe geral de mercadorias, e reúne privatização, mercadificação, monetização etc. como atributos internamente relacionados. Não faz sentido voltar a uma política de "salvar" a educação pública, pois isso é uma leitura errada do que está acontecendo.

Uma vez que os discursos analíticos sobre a privatização na educação se tornam o caminho da "educação", eles se perdem em um mar de ilusões, delírios e becos sem saída. As neblinas e os pântanos intelectuais da "educação pública", "educação por si só", "educação liberal" e afim, desviam a atenção da subsunção de instituições, processos e políticas educacionais por parte do capital, estimuladas por seus representantes e suas ideias enganosas.

O futuro de uma educação pós-capitalista deve, portanto, residir em formas alternativas: cooperativas, concretamente comunais (em vez de "comunidade" estabelecida com base no capital) e administradas por professores e estudantes e outros trabalhadores educacionais. Inicialmente, até que o capital em sua forma monetária tenha perdido seu poder, essas formas alternativas de educação devem ser financiadas (mas não executadas ou coordenadas) pelo Estado capitalista e definidas em uma trajetória pós-capitalista.

Recebido em 06/10/2017 e aprovado em 15/11/2017

\section{Notas}

1 Artigo traduzido do inglês por Diego Garcia.

2 O conceito "marketization" foi livremente traduzido por mercadificação, no sentido de que tudo se transforma em mercadoria.

3 Quantitative Easing - QE na sigla em inglês. 
4 Para a tradução deste trecho foi utilizada a edição do Grundrisse realizada pela Boitempo Editorial, com a tradução de Mário Duayer e Nélio Schneider p. 611, versão online disponível em https://nupese.fe.ufg.br/ up/208/o/Karl_Marx_-_Grundrisse_(boitempo)_completo.pdf

5 O termo commercialization é utilizado como publicidade.

6 Conforme o autor, educational aids são produtos que auxiliam os alunos a passarem nas provas (revisões, guias, livros com dicas para enfrentar provas, vídeos que ajudam a relaxar antes das provas etc).

7 marking $=$ programas / software para avaliar alunos e dar notas.

8 Para a tradução deste trecho foi utilizada a edição do Grundrisse realizada pela Boitempo Editorial, com a tradução de Mário Duayer e Nélio Schneider p. 710 e 711, versão online disponível em https://nupese. fe.ufg.br/up/208/o/Karl_Marx_-_Grundrisse_(boitempo)_completo.pdf

\section{Referências}

Ball, S. (2009) Privatising education, privatising education policy, privatising educational research: network governance and the 'competition state', Journal of Education Policy, Vol.24 No.1, pp.83-99.

CASE (2011) Our Schools are Being Privatised, Campaign for State Education Statement on Privatisation, Forum for 3-19 comprehensive education, Vol.53 No.3, pp.367-368.

Fitz, J. \& Beers, B. (2002). Education management organisations and the privatisation of public education: A cross-national comparison of the USA and Britain, Comparative Education, Vol.38 No.2, pp.137-154.

Heartfield, J. (2009) Contracting Out Authority, Critique: Journal of Socialist Theory, Vol.37 No.4, pp.683-690.

Jappe, A. (2017) The Writing on the Wall: On the Decomposition of Capitalism and its Critics, Winchester: Zer0 Books.

Klees, S. (2006) A Focus on Low-Fee Private Schools, In: C. Spreen, L. Stark \& S. Vally, Privatisation of Schools: Selling out the right to quality public education for all, Johannesburg: Centre for Education Rights and Transformation.

Kliman, A. (2012) The Failure of Capitalist Production: Underlying Causes of the Great Recession, London: Pluto Press.

Kurz, R. (2016) The Substance of Capital, trans. R. Halpin, London: Chronos Publications

Marx, K. (1858) [1973] Grundrisse: Foundations of the Critique of Political Economy (Rough Draft), Trans. M. Nicolaus, Harmondsworth: Penguin Books.

Marx, K. (1863) [1969] Theories of Surplus Value: Part 1, London: Lawrence \& Wishart.

Marx, K. (1867) [1977] Capital: A Critique of Political Economy - Volume One, London: Lawrence \& Wishart.

Marx, K. (1875) [1976] Critique of the Gotha Programme, Peking: Foreign Language Press.

McMurtry, J. (1991) Education and the Market Model, Journal of Philosophy of Education, Vol.25 No.2, pp.209-217. 
Menashy, F. (2013) Theorizing Privatization in Education: Comparing Conceptual Frameworks and the Value of the Capability Approach, Current Issues in Comparative Education, Vol.16 No.1, pp.13-25.

Mason, P. (2016) Postcapitalism: A Guide to Our Future, London: Penguin Books.

Muir, R, (2012) Not for Profit: The Role of the Private Sector in England's Schools, London: Institute for Public Policy Research.

Rikowski, G. (1990) The Recruitment Process and Labour Power, Division of Humanities \& Modern Languages, Epping Forest College, Loughton, Essex, 25th July.

Rikowski, G. (1996) Education Markets and Missing Products, a paper presented at the Conference of Socialist Economists, Annual Conference 1995, University of Northumbria, Newcastle, 7-9th July 1995. Revised version, 18th December 1996.

Rikowski, G. (2000) That Other Great Class of Commodities: Repositioning Marxist Educational Theory, a paper presented at the British Educational Research Association Annual Conference, Cardiff University, 7-10 September 2000.

Rikowski, G. (2002) Fuel for the Living Fire: Labour-Power! In: A. Dinerstein and M. Neary (eds.) The Labour Debate: An Investigation into the Theory and Reality of Capitalist Work. Aldershot: Ashgate.

Rikowski, G. (2003) The Business Takeover of Schools, Mediactive: Ideas - Knowledge -Culture, Issue 1, pp.91-108.

Rizvi, F. (2016) Privatization in Education: Trends and Consequences, Education Research and Foresight: Working Papers, No.18, Paris: UNESCO.

Roberts, M. (2016) The Long Depression: How it Happened, Why it Happened, and What Happens Next, Chicago, IL: Haymarket Books.

Ryder, A. (2017) The Commodity, a talk at 'Marx-A-Thon 1: Capital on Capitol Hill, Red May', St John's Bar and Eatery, Seattle, Washington, May 6th, 2017.

Saltman, K. (2005) The Edison Schools: Corporate Schooling and the Assault on Public Education, London: Routledge.

Saltman, K. (2006) The Right-Wing Attack on Critical and Public Education in the United States: From Neoliberalism to Neoconservatism, Cultural Politics, Vol.2 Issue 3, pp.339-358.

Saltman, K. (2007) Privatisation, in: D. Gabbard (ed.) Knowledge and Power in the Global Economy: The Effects of School Reform in a Neoliberal/Neoconservative Age, 2nd edition, London: Routledge.

Saltman, K. (2010) The Gift of Education: Public Education and Venture Philanthropy, New York, NY: Palgrave Macmillan.

Saltman, K. (2014) The Right-Wing Attack on Critical and Public Education in the United States: From Neoliberalism to Neoconservatism, Cultural Politics, Vol.2 Issue 3, pp.339-358.

Spreen, C., Stark, L. \& Vally, S. (2006) Privatisation of Schools: Selling out the right to quality public education for all, Johannesburg: Centre for Education Rights and Transformation.

Tregenna, F. (2009) 'Services' in Marxian Economic Thought, Cambridge Working Papers in Economics No.0935, Faculty of Economics, University of Cambridge, September, online at: http:// www.econ.cam.ac.uk/research/repec/cam/pdf/cwpe0935.pdf [Accessed 8th July 2017].

Srnicek, N. \& Williams, A. (2015) Inventing the Future: Postcapitalism and a World Without Work, London: Verso. 
Verger, A., Fontdevila, C. and Zancajo, A. (2016) The Privatization of Education: A Political Economy of Global Education Reform, New York Teachers College Press.

Verger, A., Steiner-Khamsi, G. \& Lubienski, C. (2017) The emerging global education industry: analysing market-making in education through market sociology, Globalisation, Societies and Education, Vol.15 No.3, pp.325-340.

TUC (2014) Education Not for Sale: A TUC Campaign Report, London: Trades Union Council. 